\title{
2014 Laboratory Directed Research Fermilab \& Development Program Plan
}
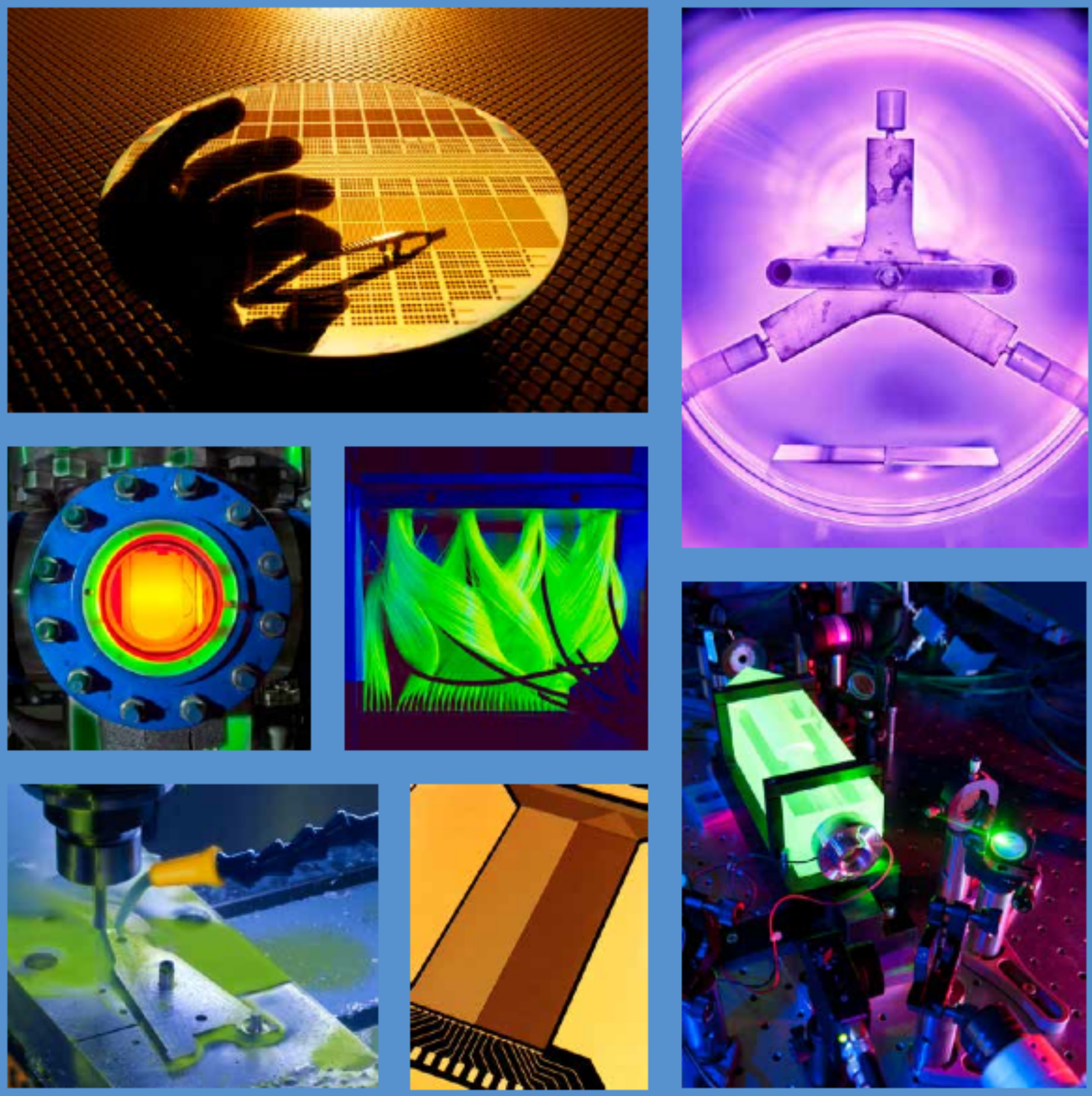

* Fermilab

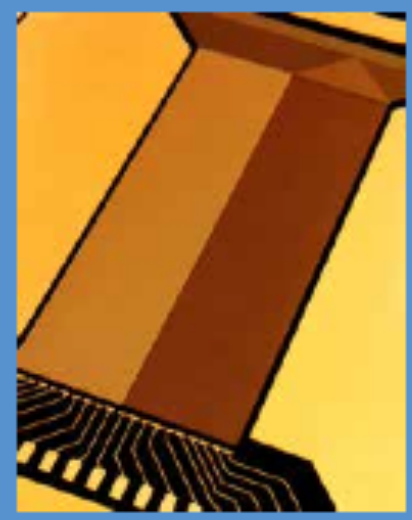

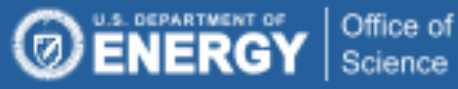


Table of Contents

LIST OF ACRONYMS USED................................................................................. ii

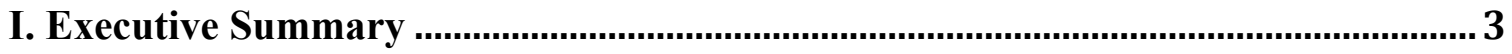

II. LDRD and Laboratory and Agency Mission ......................................................... 4

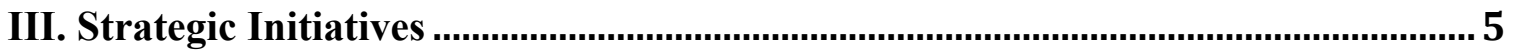

IV. FY 2014 Request

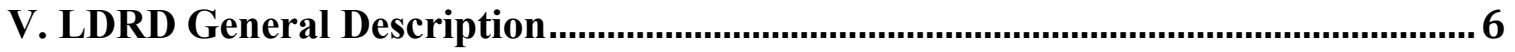

VI. LDRD Management and Administration............................................................ 8

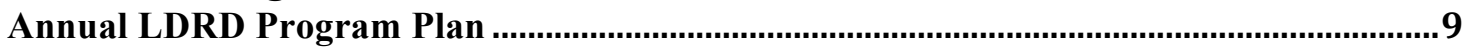

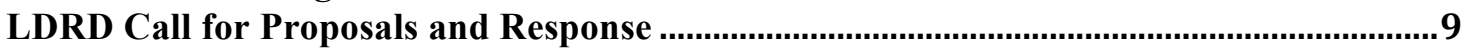

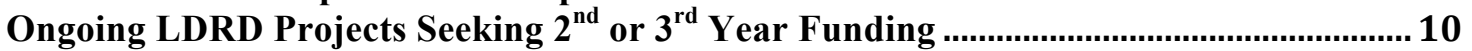

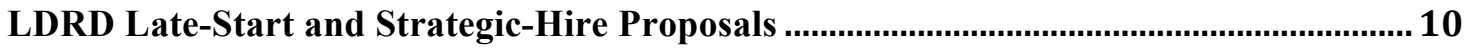

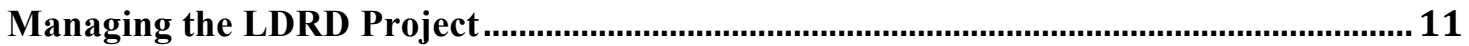

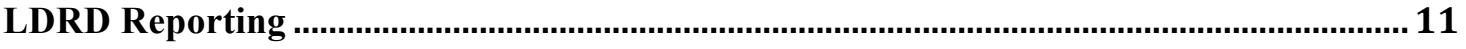

VII. Appendix

\section{LIST OF ACRONYMS USED}

$\begin{array}{ll}\text { ALDs } & \text { Associate Laboratory Directors } \\ \text { CAS } & \text { Contractor Assurance System } \\ \text { CFO } & \text { Chief Financial Officer } \\ \text { COO } & \text { Chief Operating Officer } \\ \text { CSO } & \text { Cognizant Secretarial Officer } \\ \text { DOE } & \text { Department of Energy } \\ \text { D/S/C } & \text { Division / Section / Center } \\ \text { EO } & \text { Environmental Officer } \\ \text { FFM } & \text { Field Financial Manager } \\ \text { FNAL } & \text { Fermi National Accelerator Laboratory } \\ \text { FSO } & \text { Fermi Site Office } \\ \text { FY } & \text { Fiscal Year } \\ \text { LDRD } & \text { Laboratory Directed Research and Development } \\ \text { NEPA } & \text { National Environmental Protection Act } \\ \text { NNSA } & \text { National Nuclear Security Administration } \\ \text { OHEP } & \text { Office of High Energy Physics } \\ \text { ORC } & \text { Operational Readiness Clearance } \\ \text { OSTI } & \text { Office of Science and Technical Information } \\ \text { PI } & \text { Principal Investigator } \\ \text { SO } & \text { Safety Officer }\end{array}$




\section{Executive Summary}

Fermilab is executing Laboratory Directed Research and Development (LDRD) as outlined by order DOE O 413.2B in order to enhance and realize the mission of the laboratory in a manner that also supports the laboratory's strategic objectives and the mission of the Department of Energy. LDRD funds enable scientific creativity, allow for exploration of "high risk, high payoff" research, and allow for the demonstration of new ideas, technical concepts, and devices. LDRD also has an objective of maintaining and enhancing the scientific and technical vitality of Fermilab.

LDRD is able to fund employee-initiated proposals that address the current strategic objectives and better position Fermilab for future mission needs. The request for such funds is made in consideration of the investment needs, affordability, and directives from DOE and Congress. Review procedures of the proposals will insure that those proposals which most address the strategic goals of the DOE and the Laboratory or which best position Fermilab for the future will be recommended to the Laboratory Director who has responsibility for approval. The execution of each approved project will be the responsibility of the Principal Investigator, PI, who will follow existing Laboratory guidelines to ensure compliance with safety, environmental, and quality assurance practices. A Laboratory Director-appointed LDRD Coordinator will work with Committees, Laboratory Management, other Fermilab Staff, and the PI's to oversee the implementation of policies and procedures of LDRD and provide the management and execution of this Annual Program Plan.

In FY 2014, the Fermi National Accelerator Laboratory requests that approval be granted for an LDRD expenditure comprising up to $0.4 \%(\$ 1.5 \mathrm{M})$ of the laboratory's total operating / capital equipment budget. 


\title{
II. LDRD and Laboratory and Agency Mission
}

\author{
Department of Energy Mission
}

The mission of the Energy Department is to ensure America's security and prosperity by addressing its energy, environmental and nuclear challenges through transformative science and technology solutions.

$\underline{\text { Fermilab Mission }}$

Our mission is to drive discovery in particle physics by

- building and operating world-leading accelerator and detector facilities

- performing pioneering research with global partners

- transforming technologies for science and industry

The Mission statements of Fermilab reflect the pursuit of excellence in scientific research in the area of particle physics. Particle physics addresses scientific mysteries in matter, energy, space and time through the Intensity, Energy, and Cosmic frontiers as enabled by theoretical, computational, accelerator, instrumentation and other technical capabilities. Fermilab's Mission statement reflects Fermilab's role in support of the overall mission of the Department of Energy. In particular, "transformative science and technology solutions" in the area of particle physics will be furthered through the use of LDRD where flexibility and efficiency will enable investigators to carry out creative new projects in forefront areas that enrich the current Fermilab program and strategically put Fermilab in a better position to deliver the mission objectives of DOE and Fermilab for the future. 


\section{Strategic Initiatives}

The strategic objectives of Fermilab are to establish excellence in Particle Physics, Accelerator Science and Technology, and Large-Scale User Facilities. As a facility for worldwide Users, Fermilab provides a complex that safely and efficiently delivers the highest levels of performance, provides theoretical insights, and the development of new technologies. World-class scientific, engineering, computing, and support staff use wellintegrated, efficient, business and management systems to operate Fermilab and its associated infrastructure. Providing Fermilab employees the opportunity to think creatively in terms of proposing LDRD projects and then executing those projects will likely lead to many cases where the new ideas become a seed for further investigation in the broader scope of what Fermilab can offer to DOE and its users. Beyond the immediate impact upon Fermilab and the mission of DOE, certain projects may have secondary impact on national priorities relevant to other federal agencies.

As LDRD allows for support of higher risk proposals that have the potential for higher payoff, it is not known which projects will emerge as having the greatest lasting impact. It is understood that exploratory research may result in a range of possible outcomes. Even in those cases where the result is less than desired, there may be seeds for new ideas that later become fruitful. The very process of carrying out an LDRD project will benefit the development of the Principal Investigator (PI) professionally and have a lasting impact on their ability to carry out future laboratory work. LDRD provides a flexibility that will allow for the most promising proposals to get funded and allow the investigators to see their new ideas to completion.

For this initial year of LDRD, the strategic focus will be to solicit a number of small and modest scale proposals from a broad cross section of the laboratory's staff. This initial engagement will seed additional ideas as employees and managers begin to understand the opportunities that LDRD presents. As this first call will be broad, the proposals are expected to also be broad and of a type that will extend the current programmatic areas with the possibility of advancing into new emerging areas of laboratory focus. The Laboratory Director sets this strategic focus after receiving input from the LDRD Advisory Committee, which is comprised of individuals representing many sectors of the Laboratory's scientific and technical areas. 


\section{FY 2014 Request}

In FY 2014, the Fermi National Accelerator Laboratory requests that approval be granted for an LDRD expenditure comprising up to $0.4 \%(\$ 1.5 \mathrm{M})$ of the laboratory's total operating / capital equipment budget.

The annual LDRD budget is developed after careful consideration of investment needs, affordability in our indirect budgets, directives from DOE and Congress, and compliance with order DOE O 413.2B governing the LDRD program. This total reflects that FY 2014 represents an initial year of the LDRD program at Fermilab and that the FY 2014 program will be conducted during the second half of FY 2014. The amount requested represents the best judgment to balance an initial year and start-up of the LDRD program with the funding required to meet the current programmatic deliverables while satisfying the varied demands on the laboratory overhead. While modest in scope, the request will enable the FY 2014 LDRD program to put into place an initial set of successful proposals that should realize both the specific and broader objectives of the LDRD program.

\section{LDRD General Description}

Fermilab's Laboratory Directed Research and Development seeks to fund employee initiated proposals in research and development in science and technology areas to maintain the scientific and technical vitality of the laboratory, enhance Fermilab's ability to realize its own and DOE's mission, foster creativity and exploration in forefront areas, serve as a proving ground for new concepts, and provide a means for which high-risk and potentially high-value research and development can be carried out. The program will encourage employees to think creatively and to pursue ideas in areas that support and potentially enhance the scientific and technical capabilities of the laboratory. LDRD will highlight the overall missions of the laboratory and DOE with a focus that encourages new innovative approaches to technical and scientific problems. The program will encourage exploration in new areas that may impact areas of future focus. LDRD will provide a way to initiate new ideas and perform preliminary technical assessments to determine "proof of principle" or early determination of the utility of the new idea, concept, or device. The program will facilitate the possibility of breakthrough developments in science in technology when a high-risk idea is successful. Even when the research and development reaches less desired outcomes, LDRD will provide benefits to the investigator's professional development and the laboratory's scientific and technical vitality.

The Fermilab LDRD program solicits employee proposals for research and development that are of relatively small scale both in cost and duration and yet score high on measures of excellence in terms of innovation in forefront areas of science and technology. The proposals can include experiments, theoretical studies, and simulations. Proposals can include technological development directed towards an early determination of the utility 
of the developed idea, technology, devices, or research tools. Proposals can be focused on new concepts and preliminary technical analysis of the advanced, novel experimental facility or device.

Proposals that are submitted will be evaluated on criteria that emphasize excellence in both scientific and technical merit and strategic merit. The scientific and technical significance will be judged on the importance of the proposed work to advance knowledge and understanding both within high energy physics and potentially across different fields. The proposals will also be evaluated on the innovativeness and whether the novel concepts are to be explored. In addition, the PI and others involved in the project will be evaluated on the basis of the PI's qualifications and whether the required expertise is sufficient to address the technical requirements of the proposed research plan. The proposal is expected to be of sufficient quality in clearly defining the proposed activity and making credible estimates of time and effort so that the proposed project is likely to be successfully completed within the scope of funding levels and duration. Proposals will also be evaluated in terms of the overall relevance to the missions both of the DOE and of Fermilab. The proposal will be evaluated as to its relevance of the objectives of LDRD and meeting the Laboratory's strategic goals. The evaluation process will also determine whether the proposed research and development will be likely to have enduring benefits and whether the project enhances the Laboratory's reputation in the scientific and technical community.

Under DOE O 413.2B, proposals that are funded under LDRD will also be selected only if the proposal is not already part of the programmatic portfolio of the Laboratory. In addition, each proposal is required to be completed only with LDRD funds and not supplemented with non-LDRD funds. Proposals can be for preliminary studies but cannot be used to fund construction projects or design beyond the preliminary phase. Capital expenditures are allowed for general purpose equipment that is not otherwise readily available from the Laboratory inventory.

In short, Fermilab's implementation of LDRD will address the overall objectives of the program toward providing support of research and development in novel and innovative areas where new concepts can be explored. At the same time, the presence of the program will maintain the scientific and technical vitality of the Laboratory. The proposals that will be funded will be those that demonstrate both scientific and technical merit as well as strategic merit. Successful proposals can result in new areas of exploration within Fermilab and enhance the Laboratory's and DOE's missions of pursuing scientific excellence. 


\section{LDRD Management and Administration}

With the guidance from DOE Order 413.2B and a DOE "Roles, Responsibilities, and Guidelines for LDRD at the DOE/NNSA Laboratories" guidance document dated 6/13/06, a committee of scientists, engineers, and managers met as the LDRD Advisory Committee to provide specific implementation guidance for LDRD at Fermilab for FY2014. In addition to this Annual LDRD Program Plan, a set of controlled documents describing the implementation of the Fermilab LDRD program is maintained. The LDRD Coordinator maintains these documents under the Science Management (M4) framework of the Contractor Assurance System (CAS). The LDRD Coordinator also chairs and acts as the Recording Secretary of the LDRD Advisory Committee and is an ex officio member of the LDRD Selection Committee.

The Laboratory Director is responsible for establishing the annual budget for LDRD and for setting priorities for strategic areas that will be considered by the LDRD Selection Committee. The Director appoints members of both the LDRD Advisory and Selection Committees. The Laboratory Director approves this Annual LDRD Program Plan and secures approval from DOE. The Laboratory Director is responsible for approving the final list of projects recommended to be funded and securing Fermi Site Office (FSO) approval of those projects.

The Chief Operating Officer (COO) has oversight responsibility for the Fermilab overhead budget from which LDRD is funded. Associate Laboratory Directors (ALDs) recommend topics for the annual LDRD Call for Proposals and nominate members for the LDRD Advisory and Selection Committees.

The Division, Sector, Center $(\mathrm{D} / \mathrm{S} / \mathrm{C})$ Heads provide oversight prior to the submission of both the preliminary and full proposals. This oversight should be done in consultation with other managers in the $\mathrm{D} / \mathrm{S} / \mathrm{C}$ organization along with the Supervisor of the Principal Investigator to make sure the PI is able to conduct the proposed work within the context of the PI's programmatic responsibilities and to ensure that requested resources are likely to be available for the work under the proposal. D/S/C Heads also nominate employees to serve as LDRD Reviewers and members of the LDRD Selection Committee.

The LDRD Selection Committee reviews and recommends both preliminary and full proposals. The LDRD Selection Committee recommends projects to be funded to the Laboratory Director. The Selection Committee also reviews progress reports and makes recommendations regarding $2^{\text {nd }}$ and $3^{\text {rd }}$ year funding for multi-year LDRD projects.

The Principal Investigator prepares the preliminary and full proposals and a Project Data Sheet. The PI is responsible for managing the LDRD funded project within budget and schedule constraints and for managing the project following established Laboratory guidelines including adhering to environmental, safety, and quality assurance policies and working with D/S/C Environmental (EO) and Safety (SO) Officers. The PI will work with D/S/C Field Financial Managers (FFMs) to develop the budget estimates and to 
obtain project and task codes once approved. The PI is responsible for reporting the results of the investigation preparing a required year-end Project Summary report.

\section{Annual LDRD Program Plan}

The Annual LDRD Program Plan is a required document which must be updated each fiscal year and which serves as the approval document by DOE and the Laboratory for carrying out the LDRD program annually. The LDRD Coordinator has responsibility for producing this document after taking input from the Laboratory Director, ALDs, D/S/C Heads, and the LDRD Advisory Committee. The CFO also plays a role in reviewing the draft Annual LDRD Program Plan in order to identify any possible budget issues and to provide a recommended budget level. The Laboratory Director approves a final version of the document and ensures that it is forwarded to the FSO and onto DOE for approval.

The Laboratory Director, in particular, provides high-level guidance on the strategic priorities to be emphasized in the Call for Proposals including whether an amount should be set aside for Late-Start or Strategic-Hire proposals.

This Annual LDRD Program Plan incorporates a number of elements including a one page Executive Summary that describes the objectives of the LDRD program, the level of funding being requested, and a statement of justification for that funding level in terms of the benefit to DOE and Fermilab in terms of meeting the broad mission statements of the DOE and Fermilab. The Annual LDRD Program Plan highlights the strategic priorities that the Laboratory Director wishes to emphasize.

The Plan also provides additional detail of the general description and justification of the LDRD program including the objectives, characteristics and selection criteria for LDRD Projects. The document also outlines the plan for LDRD Management and Administration. In short, the Annual LDRD Program Plan is a statement of the Laboratory's planned implementation of the LDRD program for the fiscal year.

\section{LDRD Call for Proposals and Response}

The Call for Proposals in FY2014 will be made shortly after approval of the program in order to execute an initial year LDRD program during the remainder of FY2014. The LDRD Call for Proposals will require potential PI's to submit a Preliminary Proposal along with a Full Proposal. The Call for Proposals will be advertised throughout the Laboratory in order to engage a broad spectrum of employees.

The purpose of the Preliminary Proposal is for the PI to have a discussion with the PI's line management Supervisor and the appropriate Division/Sector/Center Head to determine whether there would be any issues with the PI being able to execute the project work plan. The Preliminary Proposal is meant to be a very short document to facilitate this discussion. The Preliminary Proposal consists of a brief Project Summary and Proposed Project Work Plan. By involving the line management Supervisor and the $\mathrm{D} / \mathrm{S} / \mathrm{C}$ Head early, it is hoped that potential issues dealing with the proposed amount of 
time and other resources that the PI is expecting to spend on the LDRD project can be resolved within the organization.

The Full Proposal will be a document submitted by the PI based upon a template example. The Full Proposal will provide a Project Title and identify the Principal Investigator. The Full Proposal will list any co-investigators including additional Fermilab staff members who will charge time towards the LDRD Project along with University researchers who will collaborate on the project at no cost. The Full Proposal will have a description the proposed fiscal-year and total budgets that include fully burdened personnel costs along with required and allowable materials and service costs. The budget information will be prepared with cooperation of D/S/C Field Financial Managers. The Proposal will consist of a summary Project Description and description of the significance of the proposed project. The core component of the Full Proposal will be a description of the proposed Research Plan with a clearly stated objective of the proposed research, a description of the scientific hypothesis or technical concept to be demonstrated, the methods, materials, facilities, and techniques that will be required to carry out the research. The expected results and impact of the research and development will also be described. An emphasis will be for Full Proposals to provide clear deliverables for each fiscal year.

\section{Ongoing LDRD Projects Seeking $2^{\text {nd }}$ or $3^{\text {rd }}$ Year Funding}

For LDRD Projects that seek $2^{\text {nd }}$ or $3^{\text {rd }}$ Year Funding, it is understood that LDRD is funded out of Laboratory overhead and, as such, the availability of funds in $2^{\text {nd }}$ or $3^{\text {rd }}$ Year is contingent upon new fiscal year funding for LDRD. In addition, those LDRD Projects seeking $2^{\text {nd }}$ or $3^{\text {rd }}$ year funding will be required to make a presentation to the LDRD Selection Committee as a mid-year Progress Review. This review will allow for the Review Committee to hear a status report, ask questions, and deliberate. The LDRD Review Committee will recommend whether funding should be stopped or continued. If the project is recommended to be continued, the LDRD Review Committee also includes a recommendation as to whether the project should proceed in accordance with the original research plan or proceed contingent on specific changes. The LDRD Coordinator transmits the recommendation to the Laboratory Director for final approval.

\section{LDRD Late-Start and Strategic-Hire Proposals}

In addition to the LDRD proposals received during the Call for Proposals, LDRD has a benefit to the Laboratory to allow for responding to exceptional opportunities that might arise during the fiscal year. For example, these opportunities may target a particular new strategic area. In the case of a Late-Start proposal received after the Call for Proposals, the LDRD Coordinator will obtain concurrence of the strategic importance of the proposal with the Laboratory Director and will obtain budgetary guidance with the Chief Financial Officer to determine whether funding will fit within the approved level of LDRD funding. The LDRD Coordinator will then convene the LDRD Selection Committee to evaluate the proposal as any other LDRD proposal. LDRD Proposals may 
also be used to initiate an opportunity for a Strategic-Hire to bring to the Laboratory new capabilities.

\section{Managing the LDRD Project}

The responsibility for managing the LDRD Project lies with the PI who is required to follow Laboratory policy and procedures to be in compliance with environmental, safety, and quality assurance practices. The PI will develop the detailed work plan for the project and secure necessary approvals from the environmental and safety officers as required. The PI will work with D/S/C Heads to ensure necessary resources are available to carry out the work plan. The PI will be able to begin work on an approved LDRD project after the project and task codes are in place. The PI is responsible for expenditures under those budgetary codes. The PI will be responsible for managing all expenditures associated with the approved project and following cost-effective and efficient use of approved funds. The PI will manage the technical scope and schedule in accordance with the detailed work plan. In executing the project, the PI will be able to secure materials, services, supplies, sub-contracts according to the work plan and in compliance with allowable LDRD expenditures. The PI is responsible for tracking and controlling costs.

The LDRD Coordinator will review LDRD expenditures on a monthly basis and be available to work with the PI and Field Financial Manager to resolve any issues in the event that the Project Plan requires any modification in scope or schedule. The proposal will be written in a manner that contains a detailed budget along with an expected level of contingency within which the project will be executed. If changes to the scope or schedule are small, it is expected that they can be accommodated within the level of contingency funding. If changes to the scope or schedule are sufficiently large, the LDRD Selection Committee will review the proposed changes and make a recommendation that requires approval by the Laboratory Director. In all cases, any modifications to the scope or schedule are required to fit within the allowable cost range as spelled out in the approved Annual LDRD Program Plan.

\section{LDRD Reporting}

The DOE Order 413.2B requires a number of required documents to be produced in association with the LDRD Program. The Annual LDRD Program Plan is one required document that requires approval each fiscal year as it spells out the requested funding level, provides a general description of the LDRD program and an explanation of how the LDRD program will meet the Laboratory needs and support the DOE and Laboratory mission statements.

In addition to the Annual LDRD Program Plan, there will be an LDRD Annual Report that provides a brief program overview and individual technical reports for each active and completed LDRD project. The Project Summaries of each LDRD project will include a general description of the objectives and purpose of the project along with a summary of scientific or technical progress achieve. The Project Summaries will also contain a 
brief statement as to how the project benefited the DOE and Laboratory missions. The PI has responsibility for writing each Project Summary. The LDRD Coordinator has the responsibility of compiling those summaries along with the other material into the LDRD Annual Report. This report will be provided to the Office of Scientific and Technical Information as required by DOE Order O 413.2B.

In addition to the required annual reporting, each approved project will have a Project Data Sheet prepared by the PI to provide the FSO with sufficient background and technical information on which to base concurrence. These Project Data Sheets will provide the Laboratory name and fiscal year, a Project identifier, title, and the name of the PI. A short Project Description will explain the forefront scientific and technical aspects of the Project and a description of how the Project is tied to the mission. The Project Data Sheet will describe, if applicable, the previous year's accomplishments and the work proposed for the fiscal year.

The LDRD Coordinator will have responsibility for coordinating an annual LDRD Program Review with DOE to receive an evaluation on the compliance with DOE Order 413.2B, the LDRD program results, and the operation of the LDRD management system including the project selection process. In addition, the LDRD Coordinator will compile and make available annual performance indicators such as the numbers of graduate student and postdoctoral researchers supported under LDRD, the numbers of LDRDderived publications, invention disclosures, patents, and copyrights, and information on national awards and recognition received attributable in whole or in part to LDRD projects funded that fiscal year. The PI will provide these performance metrics to the LDRD Coordinator in an Annual LDRD Project Survey.

\section{Appendix}

The following pages consist of the current set of documents maintained under the Contractor Assurance Science Management System (M4) that outline the process and specify the roles and responsibilities for the various LDRD program steps to ensure that the Fermilab implementation of LDRD is in compliance with DOE O 413.2B and is on firm footing to realize the goals and objectives of LDRD for the betterment of the overall agency mission and the mission and future strategic initiatives of Fermilab. 


\begin{tabular}{|ll|ll|}
\hline Management System: & Science (M4) & NUMBER: & M4-6000 \\
\hline Management System Owner: & $\begin{array}{l}\text { Associate Laboratory Director for } \\
\text { Particle Physics }\end{array}$ & REVISION: & C \\
\hline Title: & LDRD Program Overview & EFFECTIVE: & 3-Mar-2014 \\
\hline
\end{tabular}

\section{Laboratory Directed Research and Development (LDRD) Program Overview}

\section{Approved by:}

\begin{tabular}{|l|l|l|}
\hline Name and Title & Signature & Date \\
\hline & & \\
\hline & & \\
\hline
\end{tabular}

\section{Revision History}

\begin{tabular}{|l|l|l|l|}
\hline Author(s) & Description & Revision & Date \\
\hline Cherri Schmidt & Initial Draft & A & 3-Mar-2014 \\
\hline Cherri Schmidt & $\begin{array}{l}\text { Add COO, FFM, and EO roles, } \\
\text { change to “one-step" process, } \\
\text { add acronyms, performance } \\
\text { metrics, reports, reviews and } \\
\text { audits }\end{array}$ & B & 21-Oct-2013 \\
\hline William Wester & FY2014 version & C & 10-Feb-2014 \\
\hline
\end{tabular}




\begin{tabular}{l|l|l|l|} 
Number: M4-6000 & Revision: C & Effective Date: 3-Mar-2014 & Page 2 of 8 \\
\hline
\end{tabular}

\subsection{Purpose}

The Laboratory Directed Research and Development (LDRD) program supports cutting-edge research across Fermilab. Its objective is to maintain the vitality of the Laboratory, enhance the Laboratory's ability to address the mission of DOE and the Laboratory, and stimulate exploration at the forefront of science and technology. LDRD projects are initiated and led by Fermilab employees and can involve collaborations with university or industrial researchers.

\subsection{Roles \& Responsibilities}

\begin{tabular}{|c|c|}
\hline Roles & Responsibilities \\
\hline Laboratory Director & 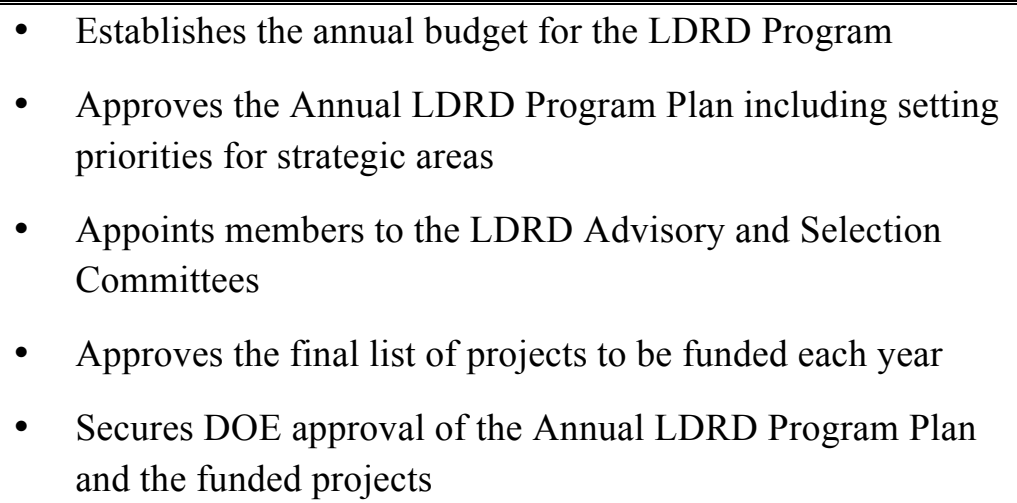 \\
\hline Chief Operating Officer & $\begin{array}{l}\text { - Oversees the impact of LDRD on the Fermilab overhead } \\
\text { budget }\end{array}$ \\
\hline Associate Lab Directors & $\begin{array}{l}\text { - } \\
\text { - Necommend topics for the Annual LDRD Call for Proposals } \\
\text { Committees members for the LDRD Advisory and Selection }\end{array}$ \\
\hline Division/Section/Center Heads & $\begin{array}{l}\text { - } \\
\text { - Puggest topics for the Annual LDRD Call for Proposals } \\
\text { submitted in consultation with other Managers and the } \\
\text { Supervisor of the Principal Investigator in their organization } \\
\text { - Nominate employees to serve as LDRD Reviewers as } \\
\text { members of the LDRD Selection Committee }\end{array}$ \\
\hline $\begin{array}{l}\text { LDRD Selection Committee } \\
\text { Member (LDRD Reviewer) }\end{array}$ & $\begin{array}{l}\text { - Review preliminary proposals and recommend invitations for } \\
\text { full proposals } \\
\text { - Review full proposals, score proposals in accordance with } \\
\text { guidance, and recommend to the Laboratory Director the list } \\
\text { of projects to be funded } \\
\text { - Review Progress Report presentations and make } \\
\text { recommendations for } 2^{\text {nd }} \text { and } 3^{\text {rd }} \text { year funding }\end{array}$ \\
\hline
\end{tabular}

No copy printed from this site is official. Before using a printed copy, verify that it is the most current version by checking the document revision on LDRD Web Page: http://ldrd.fnal.gov. 


\begin{tabular}{|c|c|c|c|}
\hline \multicolumn{4}{|c|}{ Title: LDRD Program Overview } \\
\hline Number: M4-6000 & ion: $\mathrm{C}$ & Effective Date: 3-Mar-2014 & Page 3 o \\
\hline LDRD Advisory Committee & \multicolumn{3}{|c|}{$\begin{array}{l}\text { - } \\
\text { - Review the Annual LDRD Program Plan } \\
\text { - } \\
\text { Provide other input to the LDRD Coordinator }\end{array}$} \\
\hline LDRD Coordinator & \multicolumn{3}{|c|}{$\begin{array}{l}\text { - Administers all aspects of the LDRD Program and produces } \\
\text { the required plans, reports, and other documents } \\
\text { - Serves as Recording Secretary for meetings of the LDRD } \\
\text { Advisory Committee }\end{array}$} \\
\hline Principal Investigator (PI) & \multicolumn{3}{|c|}{$\begin{array}{l}\text { - } \\
\text { - } \\
\text { Prepares preliminary and full proposals } \\
\text { - } \\
\text { - }\end{array}$} \\
\hline $\begin{array}{l}\mathrm{D} / \mathrm{S} / \mathrm{C} \text { Environmental / Safety } \\
\text { Officer }\end{array}$ & \multicolumn{3}{|c|}{$\begin{array}{ll}\text { - } & \text { Performs NEPA analysis on LDRD projects as required } \\
\text { - } & \text { Determines compliance with Laboratory safety policies }\end{array}$} \\
\hline D/S/C Field Financial Manager & \multicolumn{3}{|c|}{$\begin{array}{l}\text { - Assists PI with the development of budget estimates during } \\
\text { proposal and execution of LDRD projects } \\
\text { - Assigns the project and task codes once funds are approved } \\
\text { - Provides financial reports and tracking information }\end{array}$} \\
\hline Chief Financial Officer & \multicolumn{3}{|c|}{$\begin{array}{l}\text { Establishes the financial management systems to fund the } \\
\text { LDRD Program and track/report the use of funds, in } \\
\text { accordance with DOE requirements } \\
\text { - Advises the Laboratory Director on availability of funds and } \\
\text { budget issues as needed } \\
\text { - Provides financial data for the year-end LDRD reporting }\end{array}$} \\
\hline
\end{tabular}




\subsection{Laboratory Policies for LDRD}

3.1 The Laboratory Director determines the amount of LDRD that will be funded as an overhead expense on an annual basis. The amount may range from zero to a maximum of six percent $(6 \%)$ of the laboratory's total operating and capital equipment budgets, including non-DOE funded work.

3.2 LDRD projects must be in the forefront areas of basic and applied science and technology relevant to the mission of DOE and Laboratory. Normally LDRD projects will be relatively small and will include one or more of the following characteristics:

3.2.1 Advanced study of hypotheses, concepts, or innovative approaches to scientific, technical, or computational problems.

3.2.2 Experiments, theoretical studies, simulations, and analyses directed toward "proof of principle" or early determination of the utility of new scientific ideas, technical concepts and devices, or research tools.

3.2.3 Concept creation and preliminary technical analyses of advanced, novel experimental facilities/devices or of facilities for computational science.

3.3 LDRD will not be used to:

3.3.1 Substitute for or increase funding to any tasks for which a specific limitation has been established by Congress or DOE, or for any specific tasks that are funded by DOE or other users of the laboratory.

3.3.2 Fund projects that will require the addition of non-LDRD funds to accomplish the technical goals of the LDRD project.

3.3.3 Fund construction design beyond the preliminary phase (e.g., conceptual design, Title I design work, or any similar or more advanced design effort) or fund line-item construction projects, in whole or in part.

3.3.4 Fund general purpose capital expenditures with the exception of acquisition of general purpose equipment that is clearly required for the project and is not otherwise readily available from Laboratory inventory.

3.4 LDRD projects will be funded on an annual basis, with a maximum period of performance of 36 months. Second and third year funding is not automatic and will be contingent on the successful performance of the prior year's work.

3.5 The LDRD Program at Fermilab will be managed as a competitive proposal process, using a formal Call for Proposals.

3.5.1 The Laboratory Director shall appoint an LDRD Selection Committee to review and recommend projects for selection. 


\begin{tabular}{l|l|l|l} 
Number: M4-6000 & Revision: C & Effective Date: 3-Mar-2014 & Page 5 of 8 \\
\hline
\end{tabular}

\subsubsection{The Call for Proposals will occur at least once annually, but no more than quarterly, as detailed in the Annual LDRD Program Plan.}

3.6 The Laboratory Director may reserve a portion of the annual LDRD budget to support Exceptional Opportunities that may arise during the year, such as support of a strategic hire, special collaborations.

3.7 All LDRD proposals will be evaluated based upon scientific and technical merit and value to mission-related initiatives.

3.8 The Laboratory Director is the final authority for selecting projects for funding.

3.9 LDRD projects will be managed consistent with all other applicable requirements for similar research and development activities at the laboratory, including allowable costs.

\subsection{Supporting Procedures, Instructions, and Deployment Tools}

\begin{tabular}{|c|c|c|}
\hline Number & Title & Content \\
\hline \multicolumn{3}{|c|}{ Procedures for LDRD Funding } \\
\hline M12-6001 & Annual LDRD Program Plan & $\begin{array}{l}\text { Describes how the Annual LDRD Program Plan is prepared, } \\
\text { reviewed, and approved. }\end{array}$ \\
\hline M12-6002 & LDRD Call for Proposals & $\begin{array}{l}\text { Describes how the LDRD Call for Proposals is developed } \\
\text { and issued. }\end{array}$ \\
\hline M12-6003 & $\begin{array}{l}\text { Responding to the LDRD Call for } \\
\text { Proposals }\end{array}$ & $\begin{array}{l}\text { Describes how LDRD proposals are prepared, submitted, } \\
\text { reviewed, and approved. }\end{array}$ \\
\hline M12-6004 & $\begin{array}{l}\text { Ongoing LDRD Projects Seeking } \\
\text { Second or Third Year Funding }\end{array}$ & $\begin{array}{l}\text { Describes how ongoing LDRD projects are extended for a } \\
\text { second or third year. }\end{array}$ \\
\hline M12-6005 & $\begin{array}{l}\text { LDRD Late-Start and Strategic- } \\
\text { Hire Proposals }\end{array}$ & $\begin{array}{l}\text { Describes how LDRD late-start and strategic-hire proposals } \\
\text { are prepared, submitted, reviewed and approved. }\end{array}$ \\
\hline \multicolumn{3}{|c|}{ Procedures for Principal Investigators of Funded Projects } \\
\hline M12-6006 & Managing the LDRD Project & $\begin{array}{l}\text { Describes the principal investigator's responsibilities for } \\
\text { managing the LDRD project. }\end{array}$ \\
\hline M12-6007 & LDRD Reporting & $\begin{array}{l}\text { Describes the year-end, project-end, and post-project } \\
\text { reporting requirements and procedures. }\end{array}$ \\
\hline \multicolumn{3}{|c|}{ Procedures for Reviewers } \\
\hline M12-6008 & $\begin{array}{l}\text { Instructions for LDRD Selection } \\
\text { Committee Members and other } \\
\text { Technical Reviewers }\end{array}$ & $\begin{array}{l}\text { Describes the roles and responsibilities of the members of } \\
\text { the LDRD Selection Committee and other Technical } \\
\text { Reviewers and provides instructions for reviewing proposals }\end{array}$ \\
\hline
\end{tabular}




\begin{tabular}{l|l|l|l} 
Number: M4-6000 & Revision: C & Effective Date: 3-Mar-2014 & Page 6 of 8
\end{tabular}

\subsection{Deployment Tools (Exhibits)}
A. LDRD Project Requirements
B. Format for Annual LDRD Program Plan
C. Format for LDRD Call for Proposals
D. Format for LDRD Proposals
E. Criteria for Evaluating LDRD Proposals
F. Format for LDRD Progress Review Presentations
G. Format for Annual LDRD Project Summary

\subsection{Performance Measurement, Reporting, Reviews and Audits}

\subsection{Performance Measures}

\subsubsection{Dissemination of Scientific Results}

For LDRD projects involving discovery science, the primary measure of success is the dissemination of results to the broader scientific community. Relevant metrics include the number of refereed publications; number of other reports and publications; and presentations at conferences or symposia.

\subsubsection{Intellectual Property Protection}

For LDRD projects involving technology development, an important measure of success is the protection of potentially valuable intellectual property. Relevant metrics include the number patent disclosures (records of invention); patent applications (Fermilab or DOE elects to pursue); patents awarded; copyrights secured; licensing agreements signed; and licensing and royalty income from technologies that are successfully commercialized.

\subsubsection{Professional Staff Development}

LDRD projects are a useful mechanism for attracting, motivating, and retaining employees and enhancing the laboratory's reputation. Relevant metrics include the number of students and post-doctoral staff that are supported through LDRD projects; number of permanent staff that may be hired as a result of either the availability of LDRD funding (strategic hires) or the successful outcome of an LDRD project (expansion of the laboratory's capabilities); and awards, such as R\&D 100 Awards.

\subsubsection{Follow-on Funding Opportunities}

LDRD projects are generally expected to lead to follow-on funding from other sources. Such funding may include new or expanded funding from the DOE; new funding from other agencies, universities, and industry through a Work for Others (WFO) agreement; and Cooperative Research and Development Agreements (CRADAs) with universities and industry. 


\begin{tabular}{l|l|l|l} 
Number: M4-6000 & Revision: C & Effective Date: 3-Mar-2014 & Page 7 of 8
\end{tabular}

\subsubsection{LDRD Project Performance}

LDRD funding is an overhead expense that is shared by all research projects at the Laboratory. As such, it is incumbent on the Principal Investigators who are awarded LDRD funds to execute the projects to the highest standards of quality, cost, and schedule performance relative to plan. Relevant metrics include percentage of milestones completed; progress towards goals; and/or the status of investigation into scientific hypotheses.

\subsection{Reporting}

DOE Order 413.2B defines the following reporting requirements:

5.2.1 Submit an Annual LDRD Program Plan for approval to the Cognizant Secretarial Officer (CSO) and the responsible Site Office Manager, at least 45 days prior to the start of the fiscal year. For Fermilab, the CSO is the Director DOE Office of Science and the site office is the Fermi Site Office (FSO).

5.2.2 Annually submit a project data sheet to FSO for each LDRD project that is funded for FSO concurrence before the project is started or continued.

5.2.3 Submit an annual written report on the laboratory's LDRD activities to the CSO and FSO within 6 months after the end of the fiscal year. The report must include an overview as well as a short summary of each funded project.

5.2.4 Provide a report on completed projects to the Office of Scientific and Technical Information.

5.2.5 Collect and provide other data on the LDRD program as negotiated with DOE.

\subsection{Reviews and Audits}

5.3.1 The LDRD program is reviewed annually as part of the annual assessment of the Performance Evaluation Management Plan (PEMP).

5.3.2 All projects are reviewed at year-end during the year-end reporting of progress and results.

5.3.3 Multi-year projects are also reviewed during the Mid-Year Review process.

5.3.4 Additional reviews may be performed at the discretion of the $\mathrm{D} / \mathrm{S} / \mathrm{C}$ Heads.

5.3.5 Other reviews or audits may be scheduled by the U.S. Department of Energy Inspector General; the Office of Management and Budget (OMB); the General Accounting Office (GAO); or other federally authorized auditors. 


\begin{tabular}{l|l|l|l} 
Number: M4-6000 & Revision: C & Effective Date: 3-Mar-2014 & Page 8 of 8
\end{tabular}

\subsection{Reference Documents}

6.1.1 DOE Order 413.2B “Laboratory Directed Research and Development” Admin Chg 1

6.1.2 "Roles, Responsibilities, and Guidelines for Laboratory Directed Research and Development at the Department of Energy / National Nuclear Security Administration Laboratories," document dated 6/13/06.

6.1.3 Quality Assurance Guidelines for Scientific Research at Fermilab (M8-4200.001)

\subsection{Acronyms}

7.1 ALDs refer to the Associate Laboratory Directors.

7.2 CAS refers to the Contract Assurance System

7.3 CFO refers to the Chief Financial Officer for the Laboratory.

7.4 COO refers to the Chief Operating Officer for the Laboratory

7.5 CSO refers to the Cognizant Secretarial Officer at the U.S. Department of Energy.

7.6 DOE refers to the Department of Energy

7.7 D/S/C Heads refers to the senior managers who are responsible for each of Fermilab's major organizations (Division, Section, Center).

7.8 EO refers to Environmental Officer, who is the person within each D/S/C organization who is responsible for NEPA determinations.

7.9 FFM refers to the Field Financial Manager, who is the finance person assigned to support a specific $\mathrm{D} / \mathrm{S} / \mathrm{C} / \mathrm{P}$ organization.

7.10 FSO refers to the Fermi Site Office of the U.S. Department of Energy.

7.11 FNAL refers to the Fermi National Accelerator Laboratory

7.12 LDRD refers to Laboratory Directed Research and Development program, as defined in DOE Order 413.2B Admin Chg 1.

7.13 NEPA refers to the National Environmental Protection Act.

7.14 OHEP refers to the Office of High Energy Physics, which is the CSO for Fermilab.

7.15 ORC refers to Operational Readiness Clearance

7.16 OSTI refers to the Office of Science and Technical Information, which is responsible for disseminating scientific and technical information from U.S. Department of Energy research and development and environmental programs.

7.17 PI refers to the Principal Investigator for an individual LDRD proposal or project. 


\begin{tabular}{|l|l|l|}
\hline 닐 & Exhibits Related to M4-6000 LDRD Program & March 2014 \\
\hline
\end{tabular}

\section{Exhibit A}

\section{LDRD Project Requirements}

\section{Research Staff Eligibility}

- Any Fermilab employee may submit a proposal under the Fermilab LDRD program as the Principal Investigator or participate as a Co-Investigator. Normally, the employee will be a member of the Research or Technical Staff. Postdoctoral Research Associates may lead an LDRD project as the Principal Investigator or participate as a CoInvestigator.

- Members of the LDRD Selection Committee may participate in LDRD proposals, but are excused from the Selection Committee when their proposal or project is reviewed.

- University faculty holding a joint appointment with the Laboratory may submit proposals as a Principal Investigator with the understanding that these are Fermilab projects and that the proposed effort must primarily involve Laboratory personnel and resources. LDRD projects must benefit Fermilab and the U.S. Department of Energy.

- If an LDRD project requires expertise or capability that is not available at the Laboratory, non-Fermilab personnel may be subcontracted to fill that need, with the understanding that the LDRD must primarily involve Laboratory personnel and resources.

\section{Allowed Research}

It is a requirement of DOE Order 413.2B, the Departmental directive governing LDRD that projects shall be in the forefront areas of science and technology and include one or more of the following characteristics:

- Advanced study of hypotheses, concepts, or innovative approaches to scientific or technical problems.

- Experiments and analyses directed towards "proof of principle" or early determination of the utility of new scientific ideas, technical concepts, or devices.

- Conception and preliminary technical analyses of experimental facilities or devices.

\section{Capital Equipment}

Proposals for LDRD Funding may include a request for capital equipment if the equipment is clearly required for successful completion of the project and is not otherwise readily available from Laboratory inventory. Requests for capital equipment must include (1) the total estimated cost including overhead, and procurement charges, (2) an itemized list including the cost for each item, and (3) a justification that explains why the equipment is needed to successfully complete the proposed project and confirms that the equipment is not available at Fermilab. 


\begin{tabular}{|l|l|l|}
\hline 닐 & Exhibits Related to M4-6000 LDRD Program & March 2014 \\
\hline
\end{tabular}

Exhibit A (Page 2)

\section{LDRD Project Requirements}

\section{Allowable Costs}

Appropriate use of LDRD funds includes most activities encountered in an R\&D project such as:

- Experimental and theoretical work

- Computer modeling, simulation, and analyses

- Data gathering/collection, analysis, and reporting

- Literature searches

- Subcontracts that require an expertise or a capability not available at the Laboratory

- Domestic or foreign travel only as necessary to complete the objectives of the project (e.g., travel to a user facility or vendor)

- Materials required to successfully complete the LDRD project

Field Financial Managers (FFMs) should always be consulted if there are any questions regarding whether potential charges are allowable.

\section{Restrictions on the Use of LDRD Funds}

LDRD projects may use the existing infrastructure, equipment, and capabilities of the Laboratory. However, LDRD funds have the following restrictions:

- LDRD cannot be used to supplement DOE programmatic and Work for Others (WFO) activities and vice versa (i.e., all personnel, including fellows, postdocs, and joint faculty who work on a specific LDRD project must charge their time on the project to that LDRD project account.)

- During a project, new funding cannot be solicited to supplement or augment an LDRD project. The project objectives in the proposal approved by Laboratory management must be addressed only with the awarded LDRD funds.

- New funding which may arrive during the course of an LDRD project may be used to start a new, related activity, but cannot be used to help complete the LDRD project.

- LDRD is not to be a source of funding for travel to a conference or workshop with the only purpose of disseminating results of the LDRD efforts.

- LDRD cannot be used to fund construction line-item projects.

- LDRD cannot be used for facility maintenance.

- LDRD cannot fund general purpose capital expenditures with the exception discussed above.

- LDRD cannot be used for program development purposes such as travel to potential sponsors to market ideas or capabilities.

- LDRD cannot be used to develop and maintain capabilities of a general nature (e.g., office equipment, laptop and desktop computers, etc.) 


\begin{tabular}{|l|l|l|}
\hline בa & Exhibits Related to M4-6000 LDRD Program & March 2014 \\
\hline
\end{tabular}

\section{Exhibit B}

\section{Format for the Annual LDRD Program Plan}

The Annual LDRD Annual Plan (Plan) typically consists of 10-12 pages, inclusive of title page and tables. The text of the Plan must be single column, flush left, unjustified right margin, 12-pt Times New Roman with a 1" margin all around. The title and major sections should be set in bold type. Use block paragraphs (no indentation) with a line space between each paragraph. The footer of the final, published Plan should include the formal title of the Plan. The Plan should contain:

\section{Title Page (1 page)}

The formal title of the plan is "Fermilab Laboratory Directed Research and Development Program Plan." In addition to the Fermilab and DOE logos, the title page should clearly identify the Fiscal Year of the Plan (e.g. FY 2014).

\section{Front Matter (1 page)}

Front Matter would typically include a Table of Contents, and a List of Acronyms.

\section{Executive Summary (1 page)}

The executive summary should serve as a stand-alone, one page description of the current year request that includes (1) objectives of the program, (2) level of funding requested, and (3) justification for the level of funding in terms of benefit to DOE and Fermilab missions.

\section{Agency and Laboratory Mission and Vision}

This section should state the Agency and Laboratory Mission and Vision and provide a one to two paragraph summary of the relevance of LDRD to the Mission and Vision statements.

\section{Strategic Initiative Areas}

This section should describe the strategic focus areas for the upcoming LDRD cycle, as determined by the Laboratory Director and the LDRD Steering Committee.

\section{Resources Requested (1/2 page)}

This section should clearly state the Laboratory's request for approval of a specific LDRD expenditure level for the coming year. It may be expressed as a percent of the laboratory's budget with an estimated total amount based on the forecasted budget level or as a fixed dollar amount. The following statement should be included in this section:

The annual LDRD budget is developed after careful consideration of investment needs, affordability in our indirect budgets, directives from DOE and Congress, and compliance with order DOE $O 413.2 B$ governing the LDRD program. 


\begin{tabular}{|l|l|l|}
\hline 닐 & Exhibits Related to M4-6000 LDRD Program & March 2014 \\
\hline
\end{tabular}

\section{Exhibit B (page 2)}

\section{Format for Annual LDRD Program Plan}

\section{General Description and Justification (1-2 pages)}

This section should include the following three items of information:

- LDRD Objectives

- General Characteristics of LDRD Projects

- Selection Criteria for Funding LDRD Projects

\section{LDRD Management and Administration (4-6 pages)}

This section should briefly describe the following:

- High Level Roles and Responsibilities

- Program Management Plan, including the schedule for the coming year

- Reporting and Oversight Requirements

\section{Appendix: Additional Materials}

An Appendix will be provided as needed to expound upon additional details. For example, in FY2014, the first year of requested LDRD funding, the Appendix contains a copy of the full Process documents maintained as controlled documents under the Contractor Assurance System by the LDRD Coordinator. 


\begin{tabular}{|l|l|l|}
\hline 골 & Exhibits Related to M4-6000 LDRD Program & March 2014 \\
\hline
\end{tabular}

\section{Exhibit C}

\section{Format for Call for LDRD Proposals}

The Call for LDRD Proposals (Call) is a simple document. The text of the Call must be single column, flush left, unjustified right margin, 12-pt Times New Roman with a 1" margin all around. The title and major sections should be set in bold type. Use block paragraphs (no indentation) with a line space between each paragraph. The Call should contain:

Title: FYxx Fermilab Call for LDRD Proposals (xx are the last two digits of the fiscal year)

\section{Date of Release:}

- For a full-year funding call, the date of release is stated in the Annual LDRD Program Plan and is approved by the Laboratory Director.

- For a mid-year funding call, the data will be determined by the availability of approved LDRD funds and other strategic criteria.

\section{Purpose of the LDRD:}

Provide a one to two paragraph statement of the purpose of LDRD projects and funding. Include reference/link to M4-6000 LDRD Program Overview.

\section{Areas Considered for Funding}

List the areas of focus for the current fiscal year. Provide a percentage breakdown of how funding will be allocated (if applicable).

\section{Evaluation Criteria}

Summarize the evaluation criteria as appears in the Annual DRD Program Plan.

\section{What to Submit:}

- Preparing a Preliminary Proposal: Describe what is required in a short statement, and refer to M4-6003 Responding to the Call for LDRD Proposals for detailed guidance.

- Preparing an LDRD Proposal: Describe what is required in a short statement, and refer to M4-6003 Responding to the Call for LDRD Proposals for detailed guidance.

\section{When to Submit}

Include the scheduled milestones/due dates for the upcoming cycle.

\section{Where to Submit}

Provide email or on-line link for electronic submission. Include reminders of supervisory, D/S/C Head, and FFM review and approval requirements. Provide links "for more information". 


\begin{tabular}{|l|l|l|}
\hline בa & Exhibits Related to M4-6000 LDRD Program & March 2014 \\
\hline
\end{tabular}

\section{Exhibit D}

\section{Format for LDRD Proposals}

\section{Preliminary Proposal}

The Preliminary Proposal is a short one page document to be prepared by the Principal Investigator in consultation with their immediate line management Supervisor and the appropriate D/S/C Head. The Preliminary Proposal is intended to determine early in the process whether the PI will have expected time to conduct the proposed LDRD project and whether the scope of the proposed project fits within the ability of the $\mathrm{D} / \mathrm{S} / \mathrm{C}$ to provide necessary resources. The Preliminary Proposal will be reviewed by the LDRD Coordinator and the LDRD Selection Committee to determine early in the process whether the proposed scope of work fits within the guidelines of an LDRD Project per DOE O 413.2B.

The Preliminary Proposal should be approved and signed by the proposed Principal Investigator's immediate line management Supervisor, and the D/S/C Head or designee indicating a meeting of the minds on the scope of the proposed LDRD Project before the Full Proposal is prepared. The Preliminary Proposal consists of the following sections:

1. Project Title: Provide a descriptive title for the proposed work.

2. Principal Investigator and Co-Investigators: The name of the person proposing the LDRD project and the names of expected collaborators as Co-Investigators

3. Project Summary: A short description of the proposed project and a description as to how the project meets the objectives of LDRD

4. Project Work Plan: A short description of the project work plan and estimate of the scope of financial and human resources that will be required for the LDRD project

5. Comments or Questions: An optional section that allows the proposed Principal Investigator to seek guidance from the LDRD Coordinator and/or Selection Committee.

\section{Full Proposal}

A full proposal consists of 14 items of information as described below and is limited to 6 pages. This page limit includes figures, but does not include Items 12-14 (references, budget table, and other commitments). The text of the summary must be single column, flush left, unjustified right margin, 12-pt Times New Roman with a 1" margin all around. The title and major section should be set in bold type. Use block paragraphs (no indentation) with a line space between each paragraph. The PI should convert the file to Adobe Portable Document (pdf) format when ready to submit it to the LDRD Coordinator, following approval by the appropriate $\mathrm{D} / \mathrm{S} / \mathrm{C}$ Head.

NOTE: Full proposals may be submitted in response to an Invitation for Full Proposals (during the LDRD Annual Call for Proposals) or as Late-Start or Strategic-Hire proposals. 


\begin{tabular}{|l|l|l|}
\hline 골 & Exhibits Related to M4-6000 LDRD Program & March 2014 \\
\hline
\end{tabular}

\section{Exhibit D (page 2)}

\section{Format for LDRD Proposals}

\section{Header: Fermilab LDRD Proposal}

2. Project Title: Provide a descriptive identifier for the proposed work; avoid short titles that can be confused with other work; avoid abbreviations.

3. Principal Investigator: Only one person may be designated as the principal investigator: see the LDRD Project Requirements document for discussion on who may be the Principal Investigator of an LDRD project.

4. Lead Division/Sector/Center: This is the "home" Division/Sector/Center of the Principal Investigator.

5. Co-Investigators: List Fermilab research staff members and non-Fermilab subcontractors who will charge time to the project account. University faculty who will collaborate on the project at no cost may also be included.

6. Proposed Fiscal-Year and Total Budgets: Indicate fiscal-year operating budgets and the total project budget being requested; include Laboratory overhead factors. Also, include a requested contingency amount and justification. The budget should be prepared in consultation with the D/S/C Field Financial Manager.

7. Initiative: Indicate the LDRD topics or initiatives to which the proposal responds.

8. Project Description: Summarize in 150-200 words the scientific/technical objectives of the proposal, methods that will be used, and expected deliverables and their expected impact. This description should be understandable to a technically literate lay reader.

9. Significance (about 1-2 pages): Describe the scientific/technical problem that the proposal addresses, explain why this problem is significant, and introduce your novel approach for addressing this problem. Include a critical comparison of your proposed approach with the latest published work and explain how your project would advance the state of the art and influence its field of research. Begin with the "big picture" and funnel the reader to the significance of the specific problem addressed in the proposal.

10. Research Plan (about 3-4 pages): Provide a brief overview of your research plan and your specific objectives or aims. For each objective/aim, provide a section with the following:

a. State the objective/aim

b. Describe the scientific hypotheses to be tested or technical concepts to be demonstrated to achieve the objective/aim.

c. Discuss the methods, materials, facilities, protocols to be employed, and techniques for analyzing data and validating results as appropriate.

d. Describe the expected results and impact (e.g., fundamental breakthroughs, enabling technologies)

e. Provide a deliverable(s) for year one (within the first year of funding), year two (if seeking a multi-year project), and at the completion of the project. 


\begin{tabular}{|l|l|l|}
\hline 닐 & Exhibits Related to M4-6000 LDRD Program & March 2014 \\
\hline
\end{tabular}

\section{Exhibit D (page 3 )}

\section{Format for LDRD Proposals}

\section{Future Funding (about $1 / 2$ page):}

a. Describe how your results will be disseminated; include likely journals in which your work would be published and conferences, workshops, and planning activities at which the work would be presented.

b. List the probable future funding sources (sponsors), including DOE programs, other agencies, state agencies, or private sector investment.

c. For each probable funding source:

i. Explain how the sponsor would benefit from the pursuit of this work.

ii. Discuss probable contacts with sponsors and plans for responding to current and planned proposal calls.

iii. Estimate the likelihood that the sponsor would provide future funding including anticipated range of such funding.

12. References (not included in 6-page limit): Cite a concise set of relevant literature that supports the scientific/technical significance of your project and the innovativeness of your proposed methodologies.

\section{Resource Availability and Recent LDRD Funding (not include in 6-page limit):}

a. Discuss scientific or technical obligations of the investigators that may limit the available time for working on the LDRD project (e.g., other funded research, participation in scientific committees, etc.); use units of FTE's to estimate the time

b. List other LDRD commitments of the investigators; include both current (funded projects) and pending (new proposal) commitments; use units of FTE's to estimate the time

c. Summarize accomplishments of funded LDRD projects for the last five years (include project title, investigators, and year of project)

14. Budget Table (not included in 6-page limit): The last page of the proposal consists of a completed budget table. In the budget table, include a cost breakdown for each objective/aim discussed in the Research Plan. There is no specific budget limitation, but keep in mind that the LDRD funding has limited resources. If subcontracting work, it should be clear in the proposal what work is being subcontracted and justified why that work is not able to performed within Fermilab. 


\begin{tabular}{|l|l|l|}
\hline 리 & Exhibits Related to M4-6000 LDRD Program & March 2014 \\
\hline
\end{tabular}

\section{Exhibit E}

\section{Criteria for Evaluating LDRD Proposals}

\section{Technical Merit Criteria}

1. Scientific/Technical Significance: How important is the proposed activity to advancing knowledge and understanding within its own field and across different fields?

2. Innovativeness/Novelty: To what extent does the proposed activity explore original, innovative or novel concepts?

3. Proposer Qualifications: How well qualified are the proposers to conduct the project? Is there sufficient expertise to address all the technical requirements of the proposed research plan?

4. Proposal Quality: How well conceived and organized is the proposed activity? Are the estimates of time and effort reasonable? Is the requested level of funding, overhead charges, and level of contingency appropriate?

5. Likelihood of Success: Can the project be completed within the proposed funding levels and duration?

\section{Strategic Merit Criteria}

6. Mission Relevance: Is the proposal relevant to the missions of DOE and of the Laboratory?

7. Initiative Relevance: Does the proposed activity address the specific objectives and research priorities of the LDRD Annual Call for Proposals?

8. Strategic Fit: Does the proposed activity match well with the Laboratory's distinctive capabilities and core competencies?

9. Enduring Capability: Will the proposed new capabilities bring enduring benefit to the Laboratory? How likely will the project initiate a new program and funding?

10. Laboratory Reputation: If successful, will the project enhance the Laboratory's reputation in the scientific and technical community.

\section{Rating Scale}

\begin{tabular}{|c|l|}
\hline Number & Descriptive Responses \\
\hline $\mathbf{5}$ & Excellent, extremely interesting, novel, highest quality, absolutely \\
\hline $\mathbf{4}$ & Very good, very interesting, clever, high quality, very likely \\
\hline 3 & Good, interesting, acceptable, good quality, probably \\
\hline 2 & Fair, might be interesting, marginal, adequate, possibly \\
\hline 1 & Poor, not interesting, not acceptable, inadequate, not at all \\
\hline
\end{tabular}




\begin{tabular}{|l|l|l|}
\hline 들 & Exhibits Related to M4-6000 LDRD Program & March 2014 \\
\hline
\end{tabular}

\section{WORKSHEET FOR SCORING LDRD PROPOSAL}

\begin{tabular}{|l|l|}
\hline Proposal Name and/or ID Number & Principal Investigator's Name \\
\hline & \\
\hline
\end{tabular}

\begin{tabular}{|c|c|c|c|c|c|c|}
\hline \multirow{2}{*}{ Scoring Criteria } & \multicolumn{5}{|c|}{ Rating (Check One Per Criteria) } & \multirow{2}{*}{ Comments/Notes } \\
\hline & $\begin{array}{l}1= \\
\text { Poor }\end{array}$ & $\begin{array}{l}2= \\
\text { Fair }\end{array}$ & $\begin{array}{c}3= \\
\text { Good }\end{array}$ & $\begin{array}{c}4= \\
\text { Very } \\
\text { Good }\end{array}$ & $\begin{array}{c}5= \\
\text { Excellent }\end{array}$ & \\
\hline $\begin{array}{l}\text { Scientific/Technical } \\
\text { Significance }\end{array}$ & & & & & & \\
\hline Innovativeness/Novelty & & & & & & \\
\hline Proposer Qualifications & & & & & & \\
\hline Proposal Quality & & & & & & \\
\hline Likelihood of Success & & & & & & \\
\hline Mission Relevance & & & & & & \\
\hline Initiative Relevance & & & & & & \\
\hline Strategic Fit & & & & & & \\
\hline Enduring Capability & & & & & & \\
\hline Laboratory Reputation & & & & & & \\
\hline
\end{tabular}

Reviewer's Name (Print):

Reviewer's Signature:

Date of Review: 


\begin{tabular}{|l|l|l|}
\hline 리 & Exhibits Related to M4-6000 LDRD Program & March 2014 \\
\hline
\end{tabular}

\section{Exhibit F}

\section{Format for LDRD Progress Report Presentations}

The LDRD Progress Report Presentation is required for ongoing LDRD projects that are seeking $2^{\text {nd }}$ or $3^{\text {rd }}$ year funding. The presentation should typically consist of between 5 and 10 slides with the following content:

\section{Title Page}

Include the full title of the project as it was originally approved for funding.

Include the name of the Principal Investigator. Co-investigators are also to be listed.

\section{Project Objectives}

List the original project objectives in bullet format.

\section{Project Approach/Methods}

Provide a brief overview of the project approach and methods.

\section{Scientific/Technical Accomplishments}

Using text or figures or both, describe the accomplishments of the project during the current year. Relate them to the scientific or technical significance that were explained in the original proposal.

\section{Program Development Accomplishments}

Describes the steps that were taken or are planned to be taken to disseminate the result of the work to attract new sponsorship once your project is completed. Describe your contacts with sponsors and participation in planning activities, workshops, and current and planned proposal calls.

\section{Challenges (As Appropriate)}

List any significant changes in the research plan and why they were required, such as changes in resource availability or team composition, unexpected research results, or other challenges.

\section{Publications and Patents (As Appropriate)}

List any journal articles, conference proceedings, or patent/copyright applications derived from this project that have been published or submitted.

During the oral presentation, you should be prepared to explain whether you did or did not meet your deliverables as stated in the original proposal.

You will also be asked to indicate whether the significance has substantially changed since the project was approved and describe the steps you have taken to keep your project relevant to the needs of Fermilab and DOE. For example, did another institution publish a paper that included results that overlap with those of your LDRD project? If so, how did you adapt your research plan? 


\begin{tabular}{|l|l|l|}
\hline בa & Exhibits Related to M4-6000 LDRD Program & March 2014 \\
\hline
\end{tabular}

\section{Exhibit G}

\section{Format for Annual LDRD Project Summary}

An Annual LDRD Project Summary consists of 6 parts as described below. The text of the summary must be single column, flush left, unjustified right margin, 12-pt Times New Roman with a 1" margin all around. The title and major section should be set in bold type. Use block paragraphs (no indentation) with a line space between each paragraph. It is preferable for the document to be prepared using Microsoft Word or in Word-compatible document format.

Please remember that the LDRD Project Summary must be cleared for release to the public. For that reason, the LDRD Project Summary must adhere to the following general guidance:

- Write descriptions that are understandable to a technically literate lay reader.

- Ensure that your summary does not contain sensitive information such as unprotected intellectual property or business confidential information of an industrial partner.

- Define abbreviated terms where they first appear in the text, and place the abbreviation in parentheses immediately after the spelled-out term, such as Laboratory Directed Research and Development (LDRD).

- Use paragraphs for the descriptive parts of your summary; do not use bulleted lists, tables, or figures. If you need to describe a series, include it in a sentence [e.g., The approach offers several unique advantages: (1) list the first advantage; (2) list the second advantage; (3) list the third advantage.]

- Do not include figures, charts, tables, or any graphics; avoid using complex mathematical equations, if possible.

1. Proposal Number and Title: Use the Proposal Number assigned by the LDRD Coordinator and the full title of the original Proposal.

2. Authors: List all authors using full names. Do not include affiliations.

3. Project Description: Provide a general description of your project in a paragraph of about 150-200 words. Discuss the purpose of the project and its objectives or specific aims. Provide some context as to why this work is needed and what scientific or technical problem it will address. 


\begin{tabular}{|l|l|l|}
\hline 를 & Exhibits Related to M4-6000 LDRD Program & March 2014 \\
\hline
\end{tabular}

\section{Exhibit G (page 2)}

\section{Format for Annual Project Summary}

4. Relevance: In a paragraph of about 150-200 words, describe the relevance of the project to the missions of DOE and, if applicable, other federal agencies. Identify specific program offices within DOE or the federal agency and describe how your work benefits these programs. If your LDRD funding is completed, indicate whether you have been successful in securing follow-on funding to continue this work under new sponsorship.

5. Results and Accomplishments: In a paragraph of about 200-250 words, describe your results and accomplishments to date, key findings and impact of this work, and possible applications. Describe key deliverables of the work.

6. Publications: List all publications derived from your LDRD project. 


\begin{tabular}{|ll|ll|}
\hline Management System: & Science (M4) & NUMBER: & M4-6001 \\
\hline Management System Owner: & $\begin{array}{l}\text { Associate Laboratory Director for } \\
\text { Particle Physics }\end{array}$ & REVISION: & C \\
\hline Title: & Annual LDRD Program Plan & EFFECTIVE: & 3-Mar-14 \\
\hline
\end{tabular}

\subsection{Purpose}

This procedure describes the steps to prepare, review, and approve the Annual LDRD Program Plan. The Annual LDRD Program Plan must be submitted to the DOE Site Office for approval at least 45 days prior to the start of the new fiscal year.

\subsection{Procedure}

2.1 The LDRD Coordinator initiates a request for input for the Annual LDRD Program Plan on or before May 1 each year. The request is forwarded to the Laboratory Director, Associate Laboratory Directors, and the $\mathrm{D} / \mathrm{S} / \mathrm{C}$ Heads.

2.1.1 The Laboratory Director provides high level guidance on the strategic priorities for the LDRD program for the upcoming year.

2.1.2 The ALDs and $\mathrm{D} / \mathrm{S} / \mathrm{C}$ Heads provide input on topics, suggested changes from the prior year program, and recommend budget levels.

2.2 The LDRD Coordinator consolidates the inputs into a draft Annual LDRD Program Plan for review and comment, in accordance with Exhibit B: Format for Annual LDRD Program Plan. The target date for completion of this draft is May 15.

2.3 The LDRD Coordinator circulates the draft Annual LDRD Program Plan for review and comment. The request is directed to the ALDs and the Chief Financial Officer.

2.3.1 The ALDs may request further review and input from the $\mathrm{D} / \mathrm{S} / \mathrm{C}$ Heads that report to them. However, it is expected that the ALDs will provide a single, consolidated feedback to the LDRD Coordinator.

2.3.2 The CFO reviews the draft Annual LDRD Program Plan for the purpose of identifying potential budget issues relative to the anticipate budget for the coming year.

\subsubsection{The CFO will advise the LDRD Coordinator and the Laboratory Director on} recommended budget levels.

2.4 The Laboratory Director will establish the final, recommended LDRD budget level for the coming year, including the amount to be set aside for Late-Start or Strategic-Hire proposals.

2.4.1 The Laboratory Director will also establish the timing for the LDRD Annual Call for Proposals, which will be included in the Annual LDRD Program Plan.

2.5 The LDRD Coordinator will incorporate the feedback from all reviewers in the final draft of the Annual LDRD Program Plan and route it the ALDs and Laboratory Director for review and approval.

2.6 The Laboratory Director will forward the Annual LDRD Program Plan to the DOE at least 45 days prior to the start of the upcoming fiscal year for approval.

2.7 Once DOE has approved the Annual LDRD Program Plan, the LDRD Coordinator will publish the approved plan on the LDRD webpage. 


\begin{tabular}{|ll|ll|}
\hline Management System: & Science (M4) & NUMBER: & M4-6002 \\
\hline Management System Owner: & $\begin{array}{l}\text { Associate Laboratory Director for } \\
\text { Particle Physics }\end{array}$ & REVISION: & C \\
\hline Title: & Issuing a Call for LDRD Proposals & EFFECTIVE: & 3-Mar-14 \\
\hline
\end{tabular}

\subsection{Purpose}

This procedure describes the steps to prepare, review, approve, and release a Call for LDRD Proposals and to establish the LDRD Selection Committee for a given fiscal year. The expected number and timing of LDRD Calls for Proposals in a given fiscal year will be established in the Annual LDRD Program Plan.

\subsection{Procedure}

2.1 The LDRD Coordinator prepares a Draft Call for LDRD Proposals based on the approved Annual LDRD Program Plan and in accordance with the Format for Exhibit C: Format for Call for LDRD Proposals.

2.1.1 The draft document is forwarded to the $\mathrm{COO}$ and the Associate Laboratory Directors, and the LDRD Advisory Committee, for review and comment.

2.1.2 The $\mathrm{D} / \mathrm{S} / \mathrm{C}$ Heads provide input as requested by the LDRD Advisory Committee.

2.2 In conjunction with the first Call for LDRD Proposals in any given fiscal year, the LDRD Coordinator will also forward a Request for Nominations for the LDRD Selection Committee to the Advisory Committee, ALDs, and D/S/C Heads.

2.2.1 Appointments to the LDRD Selection Committee are for a one-year period with the possibility of being extended to a maximum of three consecutive years.

2.2.2 The LDRD Selection Committee is described in the LDRD Annual Program Plan.

2.3 The Advisory Committee returns comments on the Draft Call for LDRD Proposals and provides the LDRD Selection Committee nominations to the LDRD Coordinator.

2.4 The LDRD Coordinator updates the Call for LDRD Proposals based on the comments and prepares an LDRD Selection Committee Appointment Letters for the Laboratory Director's approval and signature (if applicable).

2.4.1 The updated Call for LDRD Proposals and LDRD Selection Committee Appointment Letter are provided to the LDRD Advisory Committee for final review.

2.4.2 Once the LDRD Advisory Committee has approved the documents, they are forwarded to the Laboratory Director for approval and signature.

2.4.3 LDRD Selection Committee Appointment Letter(s) are forwarded to the appointees.

2.5 The LDRD Selection Committee members review and recommend action for:

2.5.1 Full proposals (see M4-6003 Responding to a Call for LDRD Proposals) and

2.5.2 $2^{\text {nd }}$ and $3^{\text {rd }}$ Year Funding Requests (see M4-6004 Ongoing Projects Seeking $2^{\text {nd }}$ or $3^{\text {rd }}$ Year Funding).

2.6 Once the Laboratory Director has approved the Call for LDRD Proposals, the LDRD Coordinator issues the Call. 


\begin{tabular}{|ll|ll|}
\hline Management System: & Science (M4) & NUMBER: & M4-6003 \\
\hline Management System Owner: & $\begin{array}{l}\text { Associate Laboratory Director for } \\
\text { Particle Physics }\end{array}$ & REVISION: & C \\
\hline Title: & Responding to a Call for LDRD Proposals & EFFECTIVE: & 3-Mar-14 \\
\hline
\end{tabular}

\subsection{Purpose}

This procedure describes the steps to prepare, review, and approve proposals in response to a Call for Proposals for LDRD Funding.

\subsection{Procedure}

2.1 The Principle Investigator (PI), using the format described in Exhibit D: Format for LDRD Proposals, prepares a Preliminary Proposal that seeks concurrence between the PI, the PI's line management Supervisor, and the PI's D/S/C Head. When approved by the Supervisor and D/S/C Head, the PI submits the Preliminary Proposal as described in the Call for LDRD Proposals. The LDRD Coordinator will forward Preliminary Proposals to the LDRD Selection Committee and will transmit to the PI any comments or concerns regarding the proposed project being compliant with the requirements of the LDRD program.

2.2 The PI using the format described in Exhibit D: Format for LDRD Proposals, prepares a Full Proposal that responds to the research priorities described in the Call for LDRD Proposals.

2.2.1 The PI will develop the budget with the assistance of the Field Financial Manager (FFM) for the responsible $\mathrm{D} / \mathrm{S} / \mathrm{C}$ organization.

2.2.2 The PI is responsible for coordinating any proposals that involve more than one $\mathrm{D} / \mathrm{S} / \mathrm{C}$ organization with the $\mathrm{D} / \mathrm{S} / \mathrm{C}$ Heads and FFMs for those additional organizations.

See Exhibit A: LDRD Project Requirements for a description of research staff eligibility, allowed research, allowable costs, and restrictions on the use of LDRD funds.

2.3 The Approver, usually the D/S/C Head, reviews the Full Proposal and the project information and approves it, rejects it outright, or returns it for revision.

2.4 If returned for revision, the PI revises the Full Proposal accordingly. Once the Approver has approved the full proposal, the PI submits the proposal by the submission deadline. Steps 2.1 through 2.3 may be repeated as often as required by the Approver and PI prior to the submission deadline.

2.5 The LDRD Coordinator screens the full proposal for completeness and compliance with DOE Order 413.2B and accepts it or returns it for revision. If returned for revision, the PI revises and resubmits.

2.6 The LDRD Coordinator releases the completed proposal for review and schedules its presentation to the LDRD Selection Committee during the evaluation period identified in the LDRD Call for Proposals.

2.7 The PI prepares the presentation and submits it to the LDRD Coordinator for distribution to the LDRD Selection Committee, at least one day prior to the scheduled presentation.

2.8 The PI or alternate presents the proposal to the LDRD Selection Committee. Any member of the proposal team may give the short presentation. After the presentation, the presenters are given the opportunity to respond to questions from the LDRD Selection Committee. 


\begin{tabular}{l|l|l|l} 
Number: M4-6003 & Revision: C & Effective Date: 3-Mar-1 & Page 2 of 2
\end{tabular}

2.8.1 All proposal team members and their line managers are invited to attend the presentation and participate during the question and answer period.

2.8.2 After the presentation and question/answer session, the LDRD Selection Committee meets in a short executive session to discuss the merits of the proposal.

2.9 The LDRD Selection Committee completes its review of all proposals by the deadline established in the LDRD Call for Proposals.

2.9.1 LDRD Selection Committee members will individually rate each proposal in accordance with Exhibit E: Criteria for Evaluating LDRD Proposals.

2.9.2 The LDRD Selection Committee will meet as a team to rank all proposals and develop funding recommendations for each proposal.

See M4-6008: Instructions for LDRD Selection Committee Members for additional guidance on performing evaluations.

2.10 The LDRD Advisory Committee will review the LDRD Selection Committee recommendations and approve, reject, or modify the recommendations.

2.11 The Laboratory Director will make the final determination of projects and funding levels and forward the information to the DOE for approval. 


\begin{tabular}{|ll|ll|}
\hline Management System: & Science (M4) & NUMBER: & M4-6004 \\
\hline $\begin{array}{l}\text { Management System } \\
\text { Owner: }\end{array}$ & $\begin{array}{l}\text { Associate Laboratory Director for } \\
\text { Particle Physics }\end{array}$ & REVISION: & B \\
\hline Title: & Securing 2 ${ }^{\text {nd }}$ or 3 ${ }^{\text {rd }}$ Year Funding for Ongoing Projects & EFFECTIVE: & 3-Mar-14 \\
\hline
\end{tabular}

\subsection{Purpose}

This procedure applies to ongoing projects that are seeking second- or third-year funding.

\subsection{Procedure}

2.1 The LDRD Coordinator will schedule a mid-year Progress Review for ongoing, multi-year projects with the LDRD Selection Committee and notify the affected PIs.

2.2 The Principal Investigator (PI) of an ongoing project that is eligible for second- or third-year funding will prepare a 10-minute presentation in accordance with Exhibit F: Format for LDRD Progress Review Presentations.

2.3 The PI or alternate presents the LDRD Progress Review to the LDRD Selection Committee on the scheduled date. Any member of the proposal team may give the short presentation. After the presentation, the presenters are given the opportunity to respond to questions from the LDRD Selection Committee.

2.3.1 All proposal team members and their line managers are invited to attend the presentation and participate during the question and answer period.

2.3.2 After the presentation and question/answer session, the LDRD Selection Committee meets in a short executive session to discuss the Progress Review

2.4 The LDRD Selection Committee makes a recommendation for continued funding of the project, as follows:

2.4.1 Continue next year funding in accordance with original research plan

2.4.2 Continue next year funding contingent on specific changes in the research plan

2.4.3 Stop funding the project at the end of the current year

2.5 The LDRD Selection Committee provides a summary of recommendations for all ongoing, multi-year projects to the Steering Committee.

2.6 The LDRD Advisory Committee will review the LDRD Selection Committee recommendations and approve or modify the recommendations.

2.7 The LDRD Advisory Committee forwards the final approval or approval with comments to the LDRD Coordinator.

2.8 The LDRD Coordinator notifies the PI and the Budget Office of all final decisions. 


\begin{tabular}{|ll|ll|}
\hline Management System: & Science (M4) & NUMBER: & M4-6005 \\
\hline $\begin{array}{l}\text { Management System } \\
\text { Owner: }\end{array}$ & $\begin{array}{l}\text { Associate Laboratory Director for } \\
\text { Particle Physics }\end{array}$ & REVISION: & C \\
\hline Title: & Late-Start and Strategic-Hire Proposals & EFFECTIVE: & 3-Mar-14 \\
\hline
\end{tabular}

\subsection{Purpose}

This procedure applies to Fermilab staff members who are eligible to submit a late-start or strategichire proposal under the LDRD program. Eligibility is determined by the Director of the Laboratory, $\mathrm{COO}$ of the Laboratory, or an Associate Laboratory Director.

\subsection{Procedure}

2.1 The principal investigator (PI) who may be a strategic hire, prepares a full proposal using the format described in Exhibit D: Format for LDRD Proposals.

2.1.1 The PI will develop the budget with the assistance of the Field Financial Manager (FFM) for the responsible $\mathrm{D} / \mathrm{S} / \mathrm{C}$ organization.

2.1.2 The PI is responsible for coordinating any proposal that involves more than one $\mathrm{D} / \mathrm{S} / \mathrm{C}$ organization with the $\mathrm{D} / \mathrm{S} / \mathrm{C}$ Heads and FFMs for those additional organizations.

See the Exhibit A: LDRD Project Requirements for a description of research staff eligibility, allowed research, allowable costs, and restrictions on the use of LDRD funds.

2.2 The Approver reviews the full proposal and the project information and approves it, rejects it outright, or returns it for revision.

2.3 If returned for revision, the PI revises the full proposal accordingly. Once the Approver has approved the full proposal, the PI submits the proposal to the LDRD Coordinator.

2.4 The LDRD Coordinator screens the full proposal for completeness and compliance with DOE Order 413.2B and accepts it or returns it for revision. If returned for revision, the PI revises and resubmits.

2.5 The LDRD Coordinator schedules an evaluation of the proposal by one of the following means:

2.5.1 Convene all or part of the LDRD Selection Committee to formally review the proposal.

2.5.2 Set up an ad hoc committee to perform a review of the proposal.

2.5.3 Task two to three individual Fermilab researchers to perform a "desk-top" review.

2.6 The LDRD Selection Committee, Ad Hoc Committee, or other technical reviewers evaluate the proposal and provide comments, questions, and concerns to the LDRD Coordinator, in accordance with procedure M4-6008: Instructions for LDRD Selection Committee

\section{Members.}

2.7 After the reviews are completed, the LDRD Coordinator reviews the comments of the reviewers and forwards any questions or concerns to the PI for response.

2.8 When the LDRD Coordinator is satisfied that any questions or concerns raised by the reviewers have been adequately addressed, the LDRD Coordinator prepares a Letter of Decision for the Laboratory Director's signature, addressed to the DOE Site Office Manager. 


\begin{tabular}{l|l|l|l} 
Number: M4-6005 & Revision: C & Effective Date: 3-Mar-1 & Page 2
\end{tabular}

2.9 The Letter of Decision will be routed through the cognizant ALD to the COO for approval, modification, or rejection.

2.9.1 If approved, the Letter of Decision is forwarded to the Laboratory Director for signature.

2.9.2 If modified, the LDRD Coordinator will modify the Letter of Decision and resubmit for approval.

2.9.3 If rejected, the LDRD Coordinator will review the decision with the ALD to determine whether any steps can be taken to reverse the decision.

2.10 The Laboratory Director reviews the Letter of Decision and approves or rejects the proposal. By signing the Letter of Decision, the Laboratory Director will be concurrently approving the project and funding level and forwarding the decision to the DOE Site Office for concurrence.

2.11 Once FSO has concurred, the LDRD Coordinator will notify the PI and the Budget Office of the decision. 


\begin{tabular}{|ll|ll|}
\hline Management System: & Science (M4) & NUMBER: & M4-6006 \\
\hline Management System Owner: & $\begin{array}{l}\text { Associate Laboratory Director for } \\
\text { Particle Physics }\end{array}$ & REVISION: & C \\
\hline Title: & Managing the LDRD Project & EFFECTIVE: & 03-Mar-14 \\
\hline
\end{tabular}

\subsection{Purpose}

This procedure provides guidance to principal investigators of funded LDRD projects and key support personal for managing approved LDRD projects.

\subsection{Procedure}

2.1 Upon receipt of approval of the DOE Site Office of new research projects, the LDRD Coordinator will notify the Budget Office and the PI that a proposal has been funded, the amount that has been approved, and the relevant time period.

2.2 The Budget Office will allocate the funds and notify the PI when funding is available.

2.2.1 The information will also be provided to the Field Financial Manager (FFM) who supports the PI, as well as the PI's immediate supervisor.

2.2.2 The FFM will set up the budget code and tracking support for the PI.

2.2.3 The PI shall not begin any work prior to receiving a valid budget code from the FFM.

2.3 The Principal Investigator (PI) will plan and execute the research plan in accordance with the approved proposal and the Quality Assurance Guidelines for Scientific Research at Fermilab.

2.3.1 The PI will develop a detailed Work Plan for the project. Depending on the scope and complexity of the project, appropriate formats for the Work Plan may be a brief narrative document, a list of tasks in a spreadsheet, or tasks implemented in a scheduling tool such as Microsoft Project or Primavera P6.

2.3.2 The PI will forward the Work Plan to both the D/S/C Head, the Environmental Officer (EO), and the Safety Officer (SO) for the responsible $\mathrm{D} / \mathrm{S} / \mathrm{C}$ organization.

2.3.3 The EO will consult with the PI as needed to complete the NEPA determination.

2.3.4 The PI will update the Work Plan as needed to address any NEPA issues, safety issues, or other changes requested by the $\mathrm{D} / \mathrm{S} / \mathrm{C}$ Head.

2.3.5 Once the PI has received both approvals, the PI may begin securing materials, supplies, subcontractors, and forming collaborative agreements, such as Work for Others (WFO) and Cooperative Research and Development Agreements (CRADAs).

2.3.6 The PI will manage the technical scope and schedule, in accordance with the detailed work plan.

2.4 The PI is responsible for managing all expenditures associated with the approved project. Project expenditures must comply with allowable costs and restrictions on the use of LDRD funds as described in the Exhibit A: LDRD Project Requirements.

2.4.1 The PI is ultimately responsible for tracking and controlling all costs.

2.4.2 The FFM may assist the PI with tracking budget and expenditure information.

2.4.3 The LDRD Coordinator will monitor the overall project expenditures on a monthly 
Title: Managing the LDRD Project

\begin{tabular}{|l|l|l|l|}
\hline Number: M4-6006 & Revision: C & Effective Date: 03-Mar-14 & Page 2 of 3 \\
\hline
\end{tabular}

basis, but is not responsible for controlling costs.

2.4.4 Project expenditures must be charged directly to the project account (i.e., do not use cost transfers to allocate costs to LDRD projects).

2.4.5 Any expenditure in excess of the established budgets will require a written explanation to the LDRD Coordinator.

NOTE: LDRD is a laboratory overhead account (i.e., it is part of $G \& A$ ). Thus, funds are awarded on a fiscal-year basis and do not automatically carry over from one fiscal year to the next. Expenditures for the current fiscal year must be posted in the accounting system by September 30 to be charged against the current fiscal year budget. Subcontracts should be written so that work done in a given fiscal year can be accrued by September 30. Unless subcontractor work is accrued, invoices received after September will be charged to the next fiscal year. Procured items must be received by September 30 to be charged to the fiscal year during which the order was placed.

2.5 The PI must notify the LDRD Coordinator of any significant changes from the approved project plan. This includes scope changes, schedule changes, and any travel or other costs that were not budgeted in the approved plan.

2.5.1 Budget changes must be reviewed by the FFM prior to forwarding the information to the LDRD Coordinator and the Budget Office.

2.5.2 The $\mathrm{D} / \mathrm{S} / \mathrm{C}$ Head must review and approve any significant scope, schedule, or cost changes relative to the original Work Plan. In the event that changes exceed thresholds of $\$ 25,000$ and the lesser of a $50 \%$ increase or $\$ 200,000$, DOE review is required.

2.6 The PI is responsible for providing regular status reports to senior management.

2.6.1 $\mathrm{D} / \mathrm{S} / \mathrm{C}$ heads shall monitor performance, work with the PI to resolve issues, and alert the ALD to significant changes or issues.

2.6.2 ALDs shall monitor performance and resolve issues, approve significant changes, and resolve issues as needed.

2.6.3 The FFM will provide input to the PI for regular status reports and annual reporting as needed.

2.7 All publications such as journal articles and conference papers derived in whole or in part from LDRD project funds must follow Quality Assurance Guidelines for Scientific Research at Fermilab and the mandatory requirements of the Prime Contract with DOE.

2.7.1 The PI shall pay special attention to any intellectual property that should be protected prior to moving forward with publishing research results.

2.7.2 The PI shall notify the Office of Partnerships and Technology Transfer (OPTT) of any intellectual property that needs to be protected. 


\begin{tabular}{l|l|l|l} 
Number: M4-6006 & Revision: C & Effective Date: 03-Mar-14 & Page 3 of 3
\end{tabular}

2.7.3 The PI is responsible for completing the Record of Invention (ROI) or other documentation related to the pursuit of patents or copyrights that may arise from the research.

2.7.4 All publications resulting from the LDRD program must include the following acknowledgement:

This research has been sponsored by the Laboratory Directed Research and Development Program of Fermi National Accelerator Laboratory, managed by Fermi Research Alliance, LLC for the U.S. Department of Energy.

2.8 The PI is responsible for completing the Annual Project Summary (see Exhibit G: Format for LDRD Annual Project Summary for guidance) and the LDRD Annual Project Survey (as applicable). 


\begin{tabular}{|ll|ll|}
\hline Management System: & Science (M4) & NUMBER: & M4-6007 \\
\hline Management System Owner: & $\begin{array}{l}\text { Associate Laboratory Director for } \\
\text { Particle Physics }\end{array}$ & REVISION: & C \\
\hline Title: & LDRD Reporting Requirements & EFFECTIVE: & 03-Mar-14 \\
\hline
\end{tabular}

\subsection{Purpose}

This procedure describes the reporting requirements for the Fermilab LDRD Program.

\subsection{Procedure}

2.1 The PI is notified by the LDRD Coordinator in early September to submit the Annual LDRD Project Summary and complete the Annual LDRD Project Survey.

Note: The annual project summary should not be confused with the progress report required for continued funding. See the procedure for Ongoing Projects Seeking $2^{\text {nd }}$ and $3^{\text {rd }}$ Year Funding (M12-6004).

2.2 The PI prepares the annual project summary using the format described in the Exhibit G: Format for LDRD Annual Project Summary.

2.2.1 The PI submits the summary to the D/S/C Head and the Manager, Office of Partnerships and Technology Transfer (OPTT).

2.2.2 The $\mathrm{D} / \mathrm{S} / \mathrm{C}$ Head or his designee(s) reviews the summary following the procedure established by that $\mathrm{D} / \mathrm{S} / \mathrm{C}$ organization and completes its review.

2.2.3 OPTT will conduct the patent review concurrently with the $\mathrm{D} / \mathrm{S} / \mathrm{C}$ review and coordinate resolution of any concerns with the $\mathrm{D} / \mathrm{S} / \mathrm{C}$ Head and the PI.

2.2.4 The PI will incorporate any changes in the Annual Project Summary and provide the final, approved document in Word format to the LDRD Coordinator for compilation in to the Fermilab LDRD Program Annual Report.

2.3 The PI also completes the LDRD Annual Project Survey and submits it to the LDRD Coordinator.

2.3.1 The PI is required to complete the survey for each year that the project is funded and for three years after completion.

2.3.2 The LDRD Coordinator will compile the information and share it with the Manager of Information Resources (Business Services Section) and the Manager, OPTT

2.3.3 The Manager, Information Resources will review and work with the PI to reconcile any differences in the publications listed in the survey responses and SPIRES

2.3.4 The Manager, OPTT will review and work with the PI to reconcile any differences in the patents listed in the survey responses and the patent $\&$ licensing database 


\begin{tabular}{l|l|l|l} 
Number: M4-6007 & Revision: C & Effective Date: 03-Mar-1 & Page 2 of 2
\end{tabular}

2.4 The LDRD Coordinator compiles the LDRD Annual Project Summaries and the LDRD Annual Project Survey information into a written Fermilab LDRD Program Annual Report.

2.4.1 The Fermilab LDRD Program Annual Report will be reviewed and approved by the Associate Laboratory Directors, COO, and the Laboratory Director.

2.4.2 The Fermilab LDRD Program Annual Report will be submitted to the DOE Deputy Director for Science Programs and the DOE Site Office Manager.

2.4.3 The final, approved Fermilab LDRD Program Annual Report will also be submitted to OSTI. 